\title{
Adubação nitrogenada, inoculação e coinoculação na cultura do feijoeiro-comum
}

\section{Camila Karen Reis Barbosa ${ }^{1 *}$, Jader Nogueira dos Reis ${ }^{2}$, Giselle Prado Brigante ${ }^{3}$, Kleso Silva Franco Junior ${ }^{4}$}

\begin{abstract}
Resumo
O presente trabalho teve como objetivo avaliar a resposta do feijoeiro à inoculação, coinoculação e da adubação nitrogenada no crescimento, produção de vagens e de grãos do feijoeiro comum. O experimento foi conduzido em delineamento em blocos casualizados, com três tratamentos e sete repetições. Os tratamentos foram definidos como: (1) Testemunha, sem qualquer tratamento de sementes, com adubação nitrogenada no plantio e cobertura; (2) Inoculação com Rhizobium tropici e adubação nitrogenada de cobertura e; (3) Coinoculação com Rhizobium tropici e Azospirillum brasilense e adubação nitrogenada de cobertura. O tratamento das sementes do feijoeiro comum com inoculantes resultaram em parâmetros produtivos equivalentes ao feijoeiro adubado com fertilizantes nitrogenados minerais. Dessa forma, a inoculação e coinoculação podem substituir o adubo nitrogenado na fase inicial da cultura sem prejuízo ao número de vagens por planta, número de grãos por vagem e peso de mil grãos.
\end{abstract}

Palavras chave: Fixação biológica de nitrogênio. Azospirillum spp. Rhizobium spp.

\section{Nitrogen fertilization, inoculation and co-inoculation in commom bean culture}

\begin{abstract}
Nitrogen fertilization, inoculation and coinoculation in bean. The present work had as objective to evaluate the response of the bean to the inoculation, coinoculation and the nitrogen fertilization in the growth, production of pods and grains of the common bean. The experiment was conducted in a randomized block design with three treatments and seven replications. The treatments were defined as: (1) Control, without any seed treatment, with nitrogen fertilization at planting and cover; (2) Inoculation with Rhizobium tropici and nitrogen cover fertilization and; (3) Coinoculation with Rhizobium tropici and Azospirillum brasilense and nitrogen cover fertilization. The treatment of common bean seeds with inoculants resulted in productive parameters equivalent to common bean fertilized with mineral nitrogen fertilizer. In this way, inoculation and coinoculation can replace nitrogen fertilizer in the initial phase of the crop without prejudice to the number of pods per plant, number of grains per pod and weight of a thousand grains.
\end{abstract}

Key words: Biological nitrogen fixation. Azospirillum spp. Rhizobium spp.

\footnotetext{
${ }^{1}$ Centro Superior de Ensino e Pesquisa de Machado. Machado, Minas Gerais. Brasil. https://orcid.org/0000-0002-2219-0584

${ }^{2}$ Centro Superior de Ensino e Pesquisa de Machado. Machado, Minas Gerais. Brasil. https://orcid.org/0000-0001-9116-1448

${ }^{3}$ Centro Superior de Ensino e Pesquisa de Machado. Machado, Minas Gerais. Brasil. https://orcid.org/0000-0002-0952-0075

${ }^{4}$ Centro Superior de Ensino e Pesquisa de Machado. Machado, Minas Gerais. Brasil. https://orcid.org/0000-0002-6807-8889

*Autor para correspondência: camilakarenr@gmail.com
}

Recebido para publicação em 16 de fevereiro de 2020. Aceito para publicação em 24 de março de 2020.

e-ISSN: 2447-6218 / ISSN: 2447-6218 / (C) 2009, Universidade Federal de Minas Gerais, Todos os direitos reservados. 


\section{Introdução}

O nitrogênio é o nutriente mais absorvido pelo feijoeiro-comum e a demanda é aumentada em sistema de plantio direto, uma vez que há intensa imobilização por microrganismos do nitrogênio no solo. Por isso, técnicas que possibilitam elevar a absorção de nitrogênio pela espécie são de grande importância (Crusciol et al., 2007).

Existem quatro métodos que a planta do feijoeiro-comum consegue adquirir o nitrogênio necessário ao seu crescimento: 1) via solo, sobretudo pela decomposição da matéria orgânica; 2) pela fixação não-biológica, consequente de descargas elétricas, combustão e vulcanismo; 3) via fertilizantes nitrogenados e por último; 4) via fixação biológica do nitrogênio atmosférico (Hungria et al., 2007).

De acordo com trabalho realizado por Brito et al. (2011), a maior parte do nitrogênio acumulado pelo feijoeiro é fornecida pela fixação biológica, seguidamente pelo nitrogênio nativo do solo, derivado da decomposição da matéria orgânica e os fertilizantes (ureia). Ainda segundo os autores, o acréscimo das porções de fertilizantes nitrogenados inibe a fixação biológica do nitrogênio, sendo esta, porém, favorecida pela adubação de arranque. Brito et al. (2009) relatam que a percentagem de nitrogênio nas plantas de feijão proveniente do solo, seja via decomposição da matéria orgânica ou fertilizantes, decresceu ao longo do ciclo das culturas, sendo a contribuição destes importantes na fase inicial da cultura. Por outro lado, a percentagem de nitrogênio nas plantas de feijão proveniente da fixação simbiótica aumentou de forma quadrática ao longo do ciclo da cultura. De acordo com Hungria et al. (2001), o nitrogênio mineral proveniente dos fertilizantes está prontamente disponível às plantas, ao passo que no processo biológico, a planta demanda energia inicial para formação dos nódulos.

Por se tratar de um mineral que demanda a queima de combustíveis fósseis para sua produção e também por este motivo possuir alto custo financeiro, a adubação nitrogenada e o seu manejo configuram algumas das mais preponderantes dificuldades no cultivo do feijoeiro-comum (Souza et al., 2011; Mendes Júnior e Bueno, 2015).

O Brasil, em 2009, aderiu ao acordo de diminuir emissões de gases de efeito estufa junto à conferência das Partes (COP-15) e reafirmou esse pacto em 2010 na COP-16, no México. Com a finalidade cumprir o objetivo, foi elaborado o Plano ABC (Agricultura de Baixa Emissão de Carbono) e, dentre os desígnios estabelecidos, está a adesão das condutas agrícolas, incorporando a fixação biológica do nitrogênio (Brasil, 2012; Hungria et al., 2013a).
O feijoeiro-comum é uma leguminosa nodulífera, com potencial de realizar a simbiose mutualista via raízes com determinadas espécies de bactérias da família Rhizobiacea, conhecidas de forma genérica por rizóbios, especificamente a bactéria Rhizobium tropici. A planta aproveita o nitrogênio atmosférico fixado pelo processo de fixação biológica do nitrogênio (Hungria et al., 2001). A existência natural da bactéria no solo ou a inoculação desta via sementes possibilita a infecção da raiz da planta hospedeira, estimula o desenvolvimento de nódulos e o Rhizobium converte-se em bacterióide, que se multiplica e inicia a síntese da nitrogenase, a enzima responsável pela fixação (Hungria et al., 2001).

A prática da coinoculação ou inoculação mista intenciona a redução da aplicação de fertilizantes nitrogenados pela utilização conjunta de bactérias simbióticas e assimbióticas, as quais geram um impacto sinérgico, aumentando os resultados produtivos atingidos com os mesmos, quando utilizados em separados (Bárbaro et al., 2011).

Produtos à base de Azospirillum brasilense têm sido utilizados para a coinoculação no plantio da soja, junto com a Bradyrhizobium na Argentina e na África do Sul (Reis, 2007). A coinoculação de Rhizobium tropici e Azospirillum brasilense é uma prática tecnológica que intensificam a produção de fitohormônios pela planta e, consequentemente, o desenvolvimento radicular e a nodulação pelo rizóbio (Ribaudo et al., 2006). Algumas análises têm comprovado que a coinoculação, pode oferecer acréscimos no rendimento de culturas agrícolas, quando utilizada em conjunto (Bárbaro et al., 2011; Yadegari et al., 2010; Braccini et al., 2016).

O presente trabalho teve como objetivo avaliar a resposta do feijoeiro à inoculação, coinoculação e da adubação nitrogenada no crescimento, produção de vagens e de grãos do feijoeiro comum.

\section{Material e Métodos}

O experimento foi conduzido em Machado-MG. O município é situado a 820 metros de altitude, com as seguintes coordenadas geográficas: latitude: $21^{\circ} 40^{\prime} 29^{\prime \prime}$ Sul, Longitude: $45^{\circ} 55^{\prime} 11^{\prime \prime}$ Oeste.

O ensaio foi implementado no mês de agosto de 2018, em delineamento em blocos casualizados (DBC) e contou com três tratamentos e sete repetições, totalizando 21 unidades experimentais. Os tratamentos foram definidos como: Tratamento 1) Testemunha, sem qualquer tratamento de sementes, com adubação nitrogenada no plantio e cobertura; Tratamento 2) Inoculação com Rhizobium tropici, adubação nitrogenada de cobertura e; Tratamento 3) Coinoculação com Rhizobium tropici e Azospirillum brasilense e adubação nitrogenada de cobertura. 
Adubação nitrogenada, inoculação e coinoculação na cultura do feijoeiro-comum

Cada unidade experimental foi constituída de canteiros com área de aproximadamente $1 \mathrm{~m}^{2}$. Em cada unidade experimental foram plantadas três fileiras de doze plantas, totalizando trinta e seis plantas por parcela com espaçamento de $15 \mathrm{~cm}$ entre linhas e $10 \mathrm{~cm}$ entre as plantas.

Para a adubação nitrogenada de plantio, realizada no tratamento 1 , foi utilizada ureia protegida na dosagem de $40 \mathrm{~kg} \mathrm{ha}^{-1}$. Em todos os tratamentos foi realizada adubação em cobertura, fornecendo ureia protegida aos 32 dias após a emergência das plantas na dose de $40 \mathrm{~kg}$ ha ${ }^{-1}$.

Foram utilizadas sementes, categoria S1 da cultivar carioquinha dama, família fabaceae do grupo carioquinha. O produto comercial utilizado como fonte de Rhizobium tropici foi o inoculante turfoso Masterfix Feijão ${ }^{\circledR}$ (2x108 células viáveis por $\mathrm{mL}$ ), SEMIA 4080, na dosagem de $100 \mathrm{~g}$ do produto para cada $100 \mathrm{~kg}$ de sementes. A inoculação foi realizada à sombra, no máximo duas horas antes da semeadura e as sementes inoculadas foram mantidas protegidas do sol e do calor excessivo. Para melhor adesão da turfa, foi aplicada uma solução açucarada à $10 \% \mathrm{p} / \mathrm{p}$. Como fonte de Azospirillum brasilense foi utilizado o inoculante líquido Masterfix Gramíneas ${ }^{\circledR}$, estirpes Abv5 e Abv6 (2x108 células viáveis por $\mathrm{mL}$ ), o qual foi aplicado no sulco de semeadura nas dosagens $300 \mathrm{~mL} \mathrm{ha}^{-1}$, no momento do plantio, com o uso de pulverizador pressurizado por $\mathrm{CO}_{2}$.
As variáveis avaliadas foram número de vagens por planta (NVP), altura das plantas no florescimento (ALT), número de grãos por vagem (NGV), peso de mil grãos (PMG). As alturas das plantas foram obtidas com auxílio de régua graduada, sendo coletadas 10 plantas da fileira central de cada parcela e medidas do colo até a última vagem da planta. O número de vagens por planta foi feito da mesma maneira, coletando-se 10 plantas da fileira central de cada parcela, realizando-se a contagem das vagens e feita as médias. O número de grãos por vagem foi feito de acordo com a Regra para Análise de Sementes (Brasil, 2009). A pesagem dos grãos foi realizada com balança digital e foram coletados 100 grãos de cada parcela, totalizando 700 grãos por tratamento com a média dos pesos das 7 amostras de cada tratamento e multiplicado por dez para encontrar o peso de mil grãos.

Os dados coletados foram submetidos à análise de variância e as médias comparadas entre si pelo teste Tukey à 5\% de probabilidade por meio do programa estatístico Sisvar (Ferreira, 2019).

\section{Resultados e discussão}

O florescimento do feijoeiro ocorreu de forma simultânea entre os tratamentos aos 34 DAE, momento no qual foi realizada a avaliação de altura das plantas. De acordo com a análise de variância, houve efeito dos tratamentos apenas para a altura das plantas (Tabela 1).

Tabela 1 - Resumo da análise de variância da altura de plantas (ALT) do número de vagens por planta (NVP), número de grãos por vagem (NGV) e peso de mil grãos (PMG) de feijão submetidos à adubação nitrogenada, inoculação e coinoculação.

\begin{tabular}{llllll}
\hline \multirow{2}{*}{ F.V } & G.L & \multicolumn{3}{c}{ Quadrado Médio } \\
\cline { 3 - 6 } & & ALT (cm) & NVP & NGV & PMG (g) \\
\hline Tratamento & 2 & $926,44 * *$ & 47,38 & 1,08 & 393,08 \\
Bloco & 6 & 8,11 & 8,29 & 0,31 & 64,07 \\
Resíduo & 12 & 2,38 & 18,74 & 0,34 & 141,14 \\
\hline C.V (\%) & & 2,31 & 26,19 & 8,54 & 5,02 \\
Média & & 66,78 & 16,52 & 6,87 & 236,76 \\
\hline
\end{tabular}

**Teste $\mathrm{F}$ significativo à $1 \%$ de probabilidade.

A comparação das médias da variável altura de plantas demonstra que o tratamento 3 (Rhizobium tropice + Azospirillum brasiliense) proporcionou maior média $(78,46 \mathrm{~cm})$ em comparação aos demais tratamentos (55, $46 \mathrm{~cm}$ e $66,41 \mathrm{~cm}$ para tratamento 1 e 2 , respectivamente) (Figura 1).

Resultados semelhantes aos do presente estudo foram encontrados por Schossler et al. (2016). Esses autores verificaram diferenças significativas para altura das plantas, de modo que os tratamentos com inoculação utilizando apenas Rhizobium tropici e a coinoculação com Rhizobium tropici + Azospirillum brasiliense apre- sentaram maior altura em comparação à testemunha. A testemunha (adubação nitrogenada) apresentou menor altura provavelmente devido á quantidade menor de nitrogênio disponibilizada no tratamento ou perdas de nitrogênio por volatilização e, ou lixiviação.

Além desta, outras combinações bacterianas têm sido utilizadas com a finalidade de promover o crescimento e incrementar a produção do feijoeiro comum. Em estudo realizado por Stajković et al. (2011), cepas de Bacillus e Pseudomonas foram associadas à maior produção de matéria seca da parte aérea do feijoeiro comum quando combinadas ao Rhizobium tropice. 
Figura 1 - Médias de altura (cm) de feijoeiro-comum no estágio fenológico R5 em função da inoculação e coinoculação.

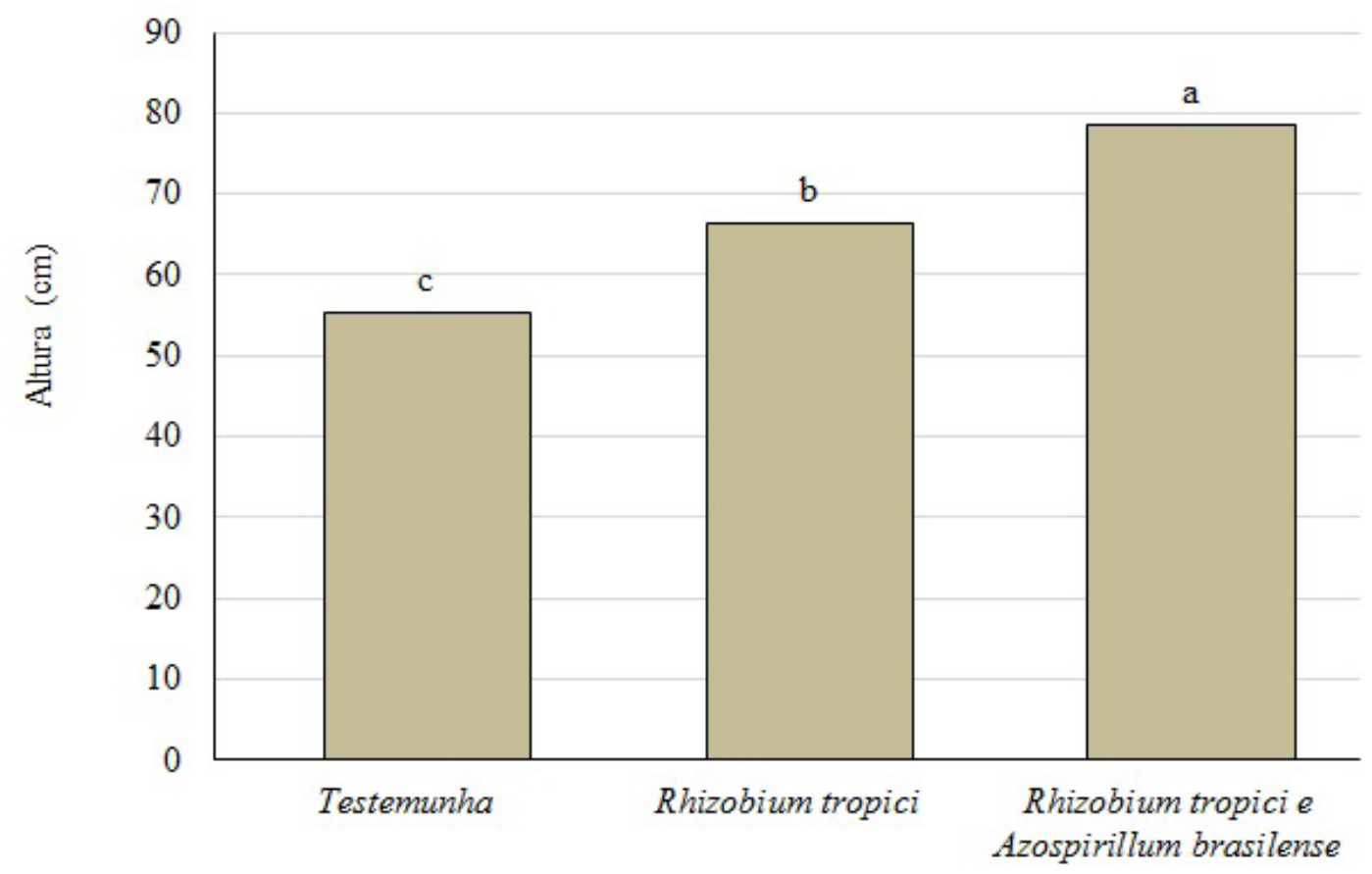

*Médias seguidas pela mesma letra não diferem estatisticamente entre si pelo teste de Tukey à 5\% de probabilidade.

Segundo Leal e Prado (2008), a deficiência em nitrogênio na planta do feijoeiro reduz significativa o desenvolvimento vegetativo, afetando diretamente à altura da planta estudada. $O$ incremento em altura de 19,7 e $41,5 \%$ nos tratamentos 2 e 3 , respectivamente podem ser explicados pelo maior aporte de nitrogênio promovido por estes tratamentos.O nitrogênio é o nutriente constituinte de aminoácidos, amidas, proteínas, ácidos nucleicos, nucleotídeos, coenzimas e hexoaminas, compostos diretamente envolvidos no desenvolvimento vegetativo das plantas. Além disso, por ser constituinte da molécula de clorofila, sua deficiência prejudica a taxa fotossintética e consequentemente a síntese de compostos de carbono (Taiz; Zeiger, 2013).

De acordo com a análise de variância não houve efeito dos tratamentos para a variável número de vagens por planta (Tabela 1), sendo o valor médio obtido de 16,52 vagens por planta. Resultado oposto aos obtidos por Peres et al. (2016) os quais encontraram menor número de vagens por planta quando utilizado o Rhizobium no segundo ano de cultivo, seja em inoculação ou coinoculação, quando comparado à testemunha, adubação nitrogenada e Azospirillum.

Fonseca et al. (2013) relatam que o número de vagens por planta é dependente da estirpe do Rhizobium utilizada. Em trabalho realizado pelos autores no qual foram avaliadas as estirpes CIAT $899^{\mathrm{T}}$ e UFLA 04-173 e oito cultivares de feijoeiro comum, foi demonstrado que a estirpe CIAT $899^{\mathrm{T}}$ proporcionou maior número de vagens e maior massa de grãos que a estirpe UFLA 04173 e estirpes nativas nas condições analisadas. Ainda segundo os autores, as estirpes apresentam diferentes especificidades ao hospedeiro e por isso demonstram comportamento diferencial e valores distintos de fixação e acúmulo de nitrogênio nas plantas. Além disso, os autores correlacionaram um maior número de vagens a um adequado manejo de irrigação (lâmina de irrigação mais próxima do valor ideal).

Ferreira et al. (2000) não encontraram variação no número de vagens por planta ao testar diferentes estirpes de Rhizobium (CIAT 899, F35, F54, F81 e CM255) no feijoeiro e reforçam que o número de vagens por planta é uma característica do cultivar, não sendo afetada pela estirpe inoculada.

Embora tenha ocorrido nodulação também na testemunha, sem inoculação, explicada pela existência natural de bactérias nativas que nodulam o feijoeiro, Araújo et al. (2007) encontraram número e massa seca de nódulos por planta superiores nos tratamentos inoculados e no tratamento com nitrogênio mineral. Para os autores, isto reforça a tese de que a inoculação com estirpes eficientes recomendadas para a cultura é necessária para aumentar a nodulação e fixação de $\mathrm{N}$ nas plantas.

Testando dose de fertilizantes nitrogenados, Soratto et al. (2004) e Crusciol et al. (2007) observaram efeito linear crescente do número de vagens por planta em razão da aplicação de adubo nitrogenado (ureia) via solo. Dessa forma, todos os tratamentos nas condições deste experimento, podem ter fornecido nitrogênio o suficiente para a máxima expressão do potencial pro- 
dutivo do feijoeiro e por isso, sem alteração do número de vagens por planta.

A análise de variância não detectou efeitos significativos dos tratamentos no número de grãos por vagem (Tabela 1) sendo a média obtida de 6,87 . Resultado semelhante ao encontrado por Araújo et al. (2007) em experimento no qual testou-se inoculação e coinoculação do feijoeiro. Os autores atribuem a indiferença do número de grãos por vagem às características genéticas de alta herdabilidade do cultivar, assim como número de vagens por planta e comprimento médio de vagens. No entanto, o resultado é oposto ao encontrado por Ferreira et al. (2000) ao testar diferentes estirpes de Rhizobium observou que a estirpe $\mathrm{F} 81$ proporcionou menor produção de grãos por vagem que a testemunha (com adubação nitrogenada), embora igual estatisticamente as demais estirpes. Entretanto, para cálculo da produtividade, esses dados foram compensados pelo número de vagens por planta, não demonstrando diferenças estatísticas entre os tratamentos. Pereira et al. (2004) também obteve diferenças, porém testando diferentes lâminas de irrigação, fator que influencia diretamente na absorção e assimilação de nitrogênio.

Em estudo realizado por Soratto et al. (2004), o número de grãos por vagem não foi influenciado pela dose de nitrogênio e sistema de produção adotado. De acordo com os autores, esta característica apresentar alta herdabilidade genética, sendo pouco influenciada pelo ambiente além da característica não apresentar correlação com a produtividade.

A análise de variância não detectou efeitos significativos no peso de mil grãos, uma vez que a menor média encontrada foi de $226 \mathrm{~g}$ para o tratamento não inoculado e os tratamentos com inoculação e coinoculação apresentaram resultados médios próximos a $242 \mathrm{~g}$. Resultado semelhante ao encontrado por Ferreira et al. (2000), os quais testaram diferentes estirpes de Rhizobium na produtividade do feijoeiro e Peres et al. (2016), os quais não observaram aumento da produtividade do feijoeiro ao avaliar a inoculação e coinoculação sob duas lâminas de irrigação apesar dos dados comprovarem aumento da nodulação da espécie no segundo ano produtivo quando realizada a coinoculação.

Em trabalho realizado por Peres et al. (2016), o rendimento de grãos $\left(\mathrm{kg} \cdot \mathrm{ha}^{-1}\right)$ em duas safras (2012 e 2013) não foi influenciado pela forma de suprimento de nitrogênio (adubação, inoculação e coinoculação). No entanto, observou-se redução do peso de cem grãos na safra 2013 quando as sementes foram coinoculadas em comparação ao uso isolado dos microrganismos e testemunha.

Souza et al. (2011) não tiveram o rendimento afetado pela inoculação com Rhizobium tropici nas sementes e foi pouco influenciado pela adubação nitrogenada. Por outro lado, Hungria et al. (2013b) realizaram cinco experimentos em dois locais (Londrina e Ponta Grossa) por três safras (2009, 2010 e 2010/11) e obtiveram maior produtividade com a coinoculação e controle não inoculado e fertilizados quando comparados aos tratamentos não inoculados controle e não fertilizado, inoculação com Rhizobium e aplicação de Azospirillum nos sulcos.

Pelo exposto, é notório que, ao contrário do que ocorre para a cultura da soja, os resultados experimentais do uso de inoculantes e coinoculantes para aumento de produtividade da cultura do feijoeiro são diversificados e altamente dependentes do ambiente, uma vez que se trata do uso de organismos vivos os quais requerem condições ambientais ótimas para sobrevivência e desenvolvimento.

\section{Conclusão}

O tratamento das sementes do feijoeiro comum com inoculantes resultaram em parâmetros produtivos equivalentes ao feijoeiro adubado com fertilizantes nitrogenados minerais. Dessa forma a inoculação e coinoculação podem substituir o adubo nitrogenado na fase inicial da cultura sem prejuízo ao número de vagens por planta, número de grãos por vagem e peso de mil grãos.

\section{Referências}

Araújo, F. F.; Carmona, F. G.; Tiritan, C. S.; Creste, J. E. 2007. Fixação biológica de N2 no feijoeiro-comum submetido a dosagens de inoculante e tratamento químico na semente comparado à adubação nitrogenada. Acta Scientiarum Agronomy, Maringá, 29: 535-540. Doi: 10.4025/ actasciagron.v29i4.416.

Bárbaro, I. M.; Júnior, L. S. B.; Machado, P. C.; Miguel, F. B. 2011. Resultados preliminares da co-inoculação de Azospirillum brasilense juntamente com Bradyrhizobium em soja. Pesquisa \& Tecnologia, 8:1-6. Disponível em: http://www.aptaregional.sp.gov. br/acesse-os-artigos-pesquisa-e-tecnologia/edicao-2011/2011julho-dezembro/853-resultados-preliminares-da-co-inoculacaode-azospirillum-juntamente-com-bradyrhizobium-em-soja/file. html?force_download=1.
Braccini, A. L; Mariucci, G. E. G.; Suzukawa, A. K.; Lima, L. H. S.; Piccinina, G. G. 2016. Co-inoculação e modos de inoculação de Bradyrhizobium japonicum e Azospirillum brasilense e adubação nitrogenada na nodulação das plantas e rendimenpara a cultura da soja. Scientia Agraria Paranaensis, 15:27-35. Doi: http://dx.doi. org/10.18188/sap.v15i1.10565.

Brito, M. de M. P.; Muraoka, T.; Silva, E. C. da. 2009. Marcha de absorção do nitrogênio do solo, do fertilizante e da fixação simbiótica em feijão-caupi (Vigna unguiculata (L.) walp.) e feijão-comum (Phaseolus vulgaris L.) determinada com uso de 15N. Revista Brasileira de Ciência do Solo, 33: 895-905. Doi: https://doi.org/10.1590/S010006832009000400014. 
Barbosa C. K. R. et al.

Brasil. Ministério da Agricultura Pecuária e Abastecimento. 2009. Regras para análises de Sementes. Ministério da Agricultura, Pecuária e Abastecimento. Regras para análise de sementes / Ministério da Agricultura, Pecuária e Abastecimento. Secretaria de Defesa Agropecuária. - Brasília : Mapa/ACS, 399 p.

Brasil. Ministério da Agricultura Pecuária e Abastecimento. 2012. Plano setorial de mitigação e de adaptação às mudanças climáticas para a consolidação de uma economia de baixa emissão de carbono na agricultura : Plano ABC (Agricultura de Baixa Emissão de Carbono) / Ministério da Agricultura, Pecuária e Abastecimento, Ministério do Desenvolvimento Agrário, coordenação da Casa Civil da Presidência da República. - Brasília : MAPA/ACS, 173 p.

Mendes Júnior, A. A.; Bueno, O. C. 2015. Participação da energia fóssil na produção dos fertilizantes industriais nitrogenados com ênfase na ureia. Energia na Agricultura, Botucatu, 30:442-447. Doi: https://doi. org/10.17224/EnergAgric.2015v30n4p442-447.

Brito, M. M. P.; Muraoka, T.; Silva, E. C. 2011. Contribuição da fixação biológica de nitrogênio, fertilizante nitrogenado e nitrogênio do solo no desenvolvimento de feijão e caupi. Bragantia, 70: 206-215. Doi: https://doi.org/10.1590/S0006-87052011000100027.

Crusciol, C. A. C.; Soratto, R. P.; Silva, L. M.; Lemos, L. B. 2007. Fontes e doses de nitrogênio para o feijoeiro em sucessão a gramíneas no sistema plantio direto. Revista Brasileira de Ciência do Solo, 31:15451552, 2007. Doi: https://doi.org/10.1590/S0100-06832007000600031.

Ferreira, A. N.; Arf, O.; Carvalho, M. A. C.; Araújo, R. S..; Sá, M. E.; Buzetti, S. 2000. Estirpes de Rhizobium tropici na inoculação do feijoeiro. Scientia Agricola, 57:507-512. Doi: https://doi.org/10.1590/ S0103-90162000000300021.

Ferreira, D. F. 2019. SISVAR: A computer analysis system to fixed effects split plot type designs. Revista Brasileira de Biometria, [S.1.], 37: 529-535. Disponível em: http://www.biometria.ufla.br/index. $\mathrm{php/BBJ/article/cite/450/ApaCitationPlugin.}$

Fonseca, G. G.; Oliveira, D. P.; Soares, B. L.; Ferreira, P. A. A.; Teixeira, C. M.; Martins, F. A. D.; Moreira, F. M. S.; Andrade, M. J. B. 2013. Resposta de cultivares de feijoeiro-comum à inoculação das sementes com duas estirpes de rizóbio. Bioscience Journal, 29: 1778-1787. Disponível em: http://www.seer.ufu.br/index.php/biosciencejournal/ article/view/21870.

Hungria, M.; Campo, R. J.; Mendes, I. C. 2001. Fixação biológica de nitrogênio na cultura da soja. Embrapa Soja. (Circular Técnica n.35) Londrina: Embrapa-Soja, 80 p. Disponível em: https://ainfo.cnptia. embrapa.br/digital/bitstream/CNPSO/18515/1/circTec35.pdf.

Hungria, M.; Campo, R.J.; Mendes, I.C. 2007. A importância do processo de fixação biológica do nitrogênio para a cultura da soja: componente essencial para a competitividade do produto brasileiro. (Documentos, 283) Londrina: EMBRAPA-SOJA, 80 p.

Hungria, M.; Mendes, I. C.; Mercante, F. M. 2013a. A fixação biológica do nitrogênio como tecnologia de baixa emissão de carbono para as culturas do feijoeiro e da soja. (Documentos, 337) Londrina: Embrapa-Soja, 24 p. Disponível em: https://www.embrapa.br/ busca-de-publicacoes/-/publicacao/964424/a-fixacao-biologica-donitrogenio-como-tecnologia-de-baixa-emissao-de-carbono-para-asculturas-do-feijoeiro-e-da-soja.
Hungria, M.; Nogueira, M. A.; Araújo, R. S. 2013b. Co-inoculação de soja e feijão comum com rizóbia e azospirila: estratégias para melhorar a sustentabilidade. Biology and Fertility of Soils, 49: 791-801.

Leal, R.; Prado, R. 2008. Desordens nutricionais no feijoeiro por deficiência de macronutrientes, boro e zinco. Revista Brasileira de Ciências Agrárias. 3: 301-306. Disponível em: http://www. nutricaodeplantas.agr.br/site/downloads/unesp_jaboticabal/omissao_ feijao9.pdf.

Pereira, J. C. R.; Rodrigues, R. A. F.; Arf, O.; Alvarez, A. C. C. 2004. Influência do manejo do solo, laminas de agua e doses de nitrogênio na produtividade do feijoeiro. Acta Scientiarum Agronomy, 26:13-19. Doi: 10.4025/actasciagron.v26i1.1949.

Peres, A. R.; Rodrigues, R. A. F; Arf, O.; Portugal, J. R.; Corsini, D. C. 2016. Co-inoculation of Rhizobium tropici and Azospirillum brasilense in common beans grown under two irrigation depths. Revista Ceres, 63:198-207. Doi: https://doi.org/10.1590/0034-737X201663020011.

Reis, V. M. 2007. Uso de bactérias fixadoras de nitrogênio como inoculante para aplicação em gramíneas. Seropédica: Embrapa Agrobiologia, 22 p. Disponível em: https://www.embrapa.br/buscade-publicacoes/-/publicacao/629377/uso-de-bacterias-fixadoras-denitrogenio-como-inoculante-para-aplicacao-em-gramineas.

Ribaudo, C. M.; Krumpholz, E. M.; Cassán, F. D.; Bottini, R.; Cantore, M.L.; Curá, J. A. 2006. Azospirillum sp. promotes root hair development in tomato plants through a mechanism that involves ethylene. Journal of Plant Growth Regulation, 25:175-185. Doi: https://doi.org/10.1007/ s00344-005-0128-5.

Schossler, J. H.; Meert, L.; Rizzardi, D. A.; Michalovicz, L. 2016. Componentes de rendimento e produtividade do feijoeiro comum submetido à inoculação e co-inoculação com estirpes de Rhizobium tropici e Azospirillum brasilense. Scientia Agraria. 17: 10-15. Doi: http://dx.doi.org/10.5380/rsa.v17i1.47409.

Soratto, R. P.; Carvalho, M. A. C. de; ARF, O. 2004. Teor de clorofila e produtividade do feijoeiro em razão da adubação nitrogenada. Pesquisa Agropecuária Brasileira, 39:895-901. Doi: https://doi.org/10.1590/ S0100-204X2004000900009.

Souza, E. F. C.; Soratto, R. P.; Pagani, F. A. 2011. Aplicação de nitrogênio e inoculação com rizóbio em feijoeiro-comum cultivado após milho consorciado com braquiária. Pesquisa Agropecuária Brasileira, 46: 370-377. Doi: https://doi.org/10.1590/S0100-204X2011000400005.

Stajković, O.; Delić, D.; Jošić, D; Kuzmanović, D.; Rasulić, N.; KneževićVukčević, J. 2011. Improvement of common bean growth by coinoculation with Rhizobium and plant growth-promoting bactéria. Romanian Biotechnological Letters, 16: 5919-5926.

Taiz, L.; Zeiger, E. 2013. Fisiologia vegetal. 5.ed. Porto Alegre:Artemed, 954p.

Yadegari, M. Rahmani, A.; Noormohammadi, G.; Ayneband, A. 2010. Plant growth promoting rhizobacteria increase growth, yield and nitrogen fixation in Phaseolus vulgaris. Journal of Plant Nutrition, 33: 1733-1743. Doi: 10.10 01904167.2010.503776. 